\title{
Dynamic Aspects of Solid Solution Cathodes for Electrochemical Power Sources
}

\author{
Atlung, Sven; West, Keld; Jacobsen, Torben
}

Published in:

Journal of The Electrochemical Society

Link to article, DOI:

$10.1149 / 1.2129269$

Publication date:

1979

Document Version

Publisher's PDF, also known as Version of record

Link back to DTU Orbit

Citation (APA):

Atlung, S., West, K., \& Jacobsen, T. (1979). Dynamic Aspects of Solid Solution Cathodes for Electrochemical Power Sources. Journal of The Electrochemical Society, 126(8), 1311-1321. https://doi.org/10.1149/1.2129269

\section{General rights}

Copyright and moral rights for the publications made accessible in the public portal are retained by the authors and/or other copyright owners and it is a condition of accessing publications that users recognise and abide by the legal requirements associated with these rights.

- Users may download and print one copy of any publication from the public portal for the purpose of private study or research.

- You may not further distribute the material or use it for any profit-making activity or commercial gain

- You may freely distribute the URL identifying the publication in the public portal

If you believe that this document breaches copyright please contact us providing details, and we will remove access to the work immediately and investigate your claim. 


\title{
Dynamic Aspects of Solid Solution Cathodes for Electrochemical Power Sources
}

\author{
S. Atlung, $K$. West, and T. Jacobsen \\ Fysisk-Kemisk Institut, Technical University of Denmark, DK 2800 Lyngby, Denmark
}

\begin{abstract}
Battery systems based on alkali metal anodes and solid solution cathodes, i.e., cathodes based on the insertion of the alkali cation in a "host lattice," show considerable promise for high energy density storage batteries. This paper discusses the interaction between battery requirements, in particular for vehicle propulsion, and electrochemical and constructional factors. It is argued that the energy obtainable at a given load is limited by saturation of the surface layers of cathode particles with cations, and that the time before saturation occurs is determined by diffusion of cations and electrons into the host lattice. Expressions are developed for plane, cylindrical, and spherical particles, giving the relation between battery load and the amount of cathode material utilized before saturation. The particle shape and a single parameter $Q$ is used to describe cathode performance. $Q$ is the ratio between discharge time at $100 \%$ utilization of the cathode at the given load, and the time constant for diffusion through the cathode particles. This description is extended to cover short peak loads characteristic of vehicle propulsion. On the basis of estimated parameters for the $\mathrm{Li} / \mathrm{TiS}_{2}$ couple with $\mathrm{LiClO}_{4}$-propylenecarbonate electrolyte the properties of plane cathodes or cathodes consisting of few layers of particles are examined in relation to traction requirements. In this context limiting currents in the electrolyte phase are discussed, and a relation between the maximal allowed values for particle size and electrode spacing is derived. For nonporous electrodes the limiting factor is cathode surface saturation. A qualitative discussion of porous cathodes indicates that the cathode thickness, and thus the over-all specific energy, is limited by cation transport in the pore electrolyte when the cation diffusion coefficient in the solid exceeds $10^{-10} \mathrm{~cm}^{2} \mathrm{sec}^{-1}$. On the basis of an approximate relation between cathode thickness and electrode spacing the specific energy for the $\mathrm{Li} / \mathrm{TiS}_{2}$ system with organic electrolyte is estimated to be 120$150 \mathrm{~W}-\mathrm{hr} / \mathrm{kg}$ in agreement with published values.
\end{abstract}

The development of advanced secondary battery systems for vehicle propulsion and load levelling has created considerable interest in high energy electrode couples and means to adopt these for practical battery systems.

To obtain high specific energy and power the cell reaction should have a high affinity, and include as few phases and kinetic steps as possible. In this respect cathodes based on nonstoichiometric compounds able to accommodate large quantities of cations without phase changes are very attractive. A class of these compounds is intercalation or solid solution materials as reviewed by Steele (1). Combined with anodes utilizing alkali or alkaline earth metals the requirements above are met in an ideal way. The cell reaction in this case is

$$
\delta A+\mathrm{H}\left(A^{+}, e^{-}\right)_{x}=\mathrm{H}\left(A^{+}, e^{-}\right)_{x+\delta}
$$

where the alkali metal cation together with an electron are inserted in the "host lattice" without producing new phases or disrupting this lattice as long as $x$ stays inside a certain homogeneous range. To obtain high specific energy a low chemical potential of the inserted cation and a wide homogeneous range for $x$ is

- Electrochemical Society Active Member.

Key words: battery, diffusion, power. required. In the event that the host lattice is based on a transition metal compound, the inserted cation can retain its ionic nature [Silbernagel (3)] as the electron can be accommodated in the electronic structure of the host lattice. This gives the desired low chemical potential and enhances the reversibility of the cathodic reaction.

To obtain high specific power the transport of the cation-electron pair in the host lattice should be fast. Therefore suitable materials for solid solution cathodes have a high electronic conductivity and a high mobility for inserted cations. These requirements are met by some layered compounds where cations can be accommodated between the anion planes where only weak van der Waals forces are present.

Wittingham (4) and Steele (2) have given extensive reviews of these materials. In particular the diand trichalcogenides of the transition metals are promising materials [Broadhead (5), Wittingham (6)] and among these $\mathrm{TiS}_{2}$ appears to be the preferred material today.

In relation to the solid solution electrode materials mentioned above, it is of interest to note that the cathodes in two of the "classical" battery systems, viz., the secondary $\mathrm{Ni} / \mathrm{Cd}$ system and the primary $\mathrm{MnO}_{2} / \mathrm{Zn}$ battery, work as solid solution electrodes. 
As early as 1946 Colemann (7) proposed that the cathodic process in the $\mathrm{MnO}_{2}$ cathode was

$$
\mathrm{MnO}_{2}+\mathrm{H}^{+}+e^{-}=\mathrm{MnOOH}
$$

and that the rate controlling process was diffusion of protons in the cathodic material.

This theory has been developed further by several workers [Scott (8), Bode (9), Kozawa (10), and Gabano (11)].

Recently it has been shown by Ikeda (12) that $\mathrm{Li}^{+}$ can be inserted in some types of $\gamma-\mathrm{MnO}_{2}$; there is, however, some doubt as to the reversible range of $x$ for the manganese dioxides. For the $\mathrm{NiOOH} / \mathrm{Ni}(\mathrm{OH})_{2}$ electrode, Lukovtsev (13) proposed the insertion of protons in the lattice, and Tuomi (14) developed the theory further. Mac Arthur $(15,16)$ determined the proton diffusion coefficients in the NiOOH lattice.

It is worth noting that the cathodes based on the insertion of protons cannot attain the specific energy of systems like $\mathrm{Li} / \mathrm{TiS}_{2}$ as long as the anodic reaction does not produce $\mathrm{H}^{+}$. In the following a battery system with an alkali metal anode and a solid solution cathode, where the alkali cation can be inserted according to [1] will be discussed in relation to a given application.

The solid solution battery systems have as a rule high stoichiometric specific energy contents, but the crucial point is how much these are reduced when the system is adapted to practical battery use. This will to a large extent depend on the ratio between the rate capabilities of the cathode/electrolyte system and the power required from the battery.

\section{Rate Limitations in the Cathodic Process}

One of the advantages expected from the use of solid solution electrodes is a small transfer overvoltage, because the charge transfer process does not depend on electron transfer between an electron conducting metal and a redox system in an ion conducting electrolyte.

In solid solution electrodes the electrons are transferred from the metal into the electron-conducting cathode material. The cations are likewise transferred between the electrolyte and the solid solution, both phases being solvents for the cation.

These processes are probably fast and consequently the cathodic processes are treated as reversible with a negligible transfer overvoltage.

In this work the anodic processes are not treated in detail, and the associated overvoltages are neglected in the following. Thus the overvoltage terms influencing the battery terminal voltage originate mainly from transport of the cations in the electrolyte and in the solid solution electrode.

The transport in the electrolyte depends on which type of electrolyte-solid ion conductor, molten salts, or organic solutions-is used. In the following we assume that an electrolyte consisting of a 1,1 salt of the anode metal dissolved in an organic solvent is used. With this type of electrolyte the cation transport is driven as well by the electric field as by a concentration gradient, whose magnitude depends on the cation diffusion coefficient.

Materials used for solid solution cathodes usually have a high electronic conductivity. Therefore the electric field in the cathode during current flow is low, and the cation transport in the solid will take place through chemical diffusion, resulting in a concentration gradient between the surface and the interior of the cathode.

These phenomena are illustrated in Fig. 1 which depicts the cation concentration profiles during discharge and charge. According to the discussion above, the behavior of the system under load is controlled by the interfacial concentrations $c_{\mathrm{A}}{ }^{*}$ and $c_{\mathrm{C}}{ }^{*}$ in the electrolyte, and $c_{\mathrm{S}}$ " in the cathode.
DISCHARGE:

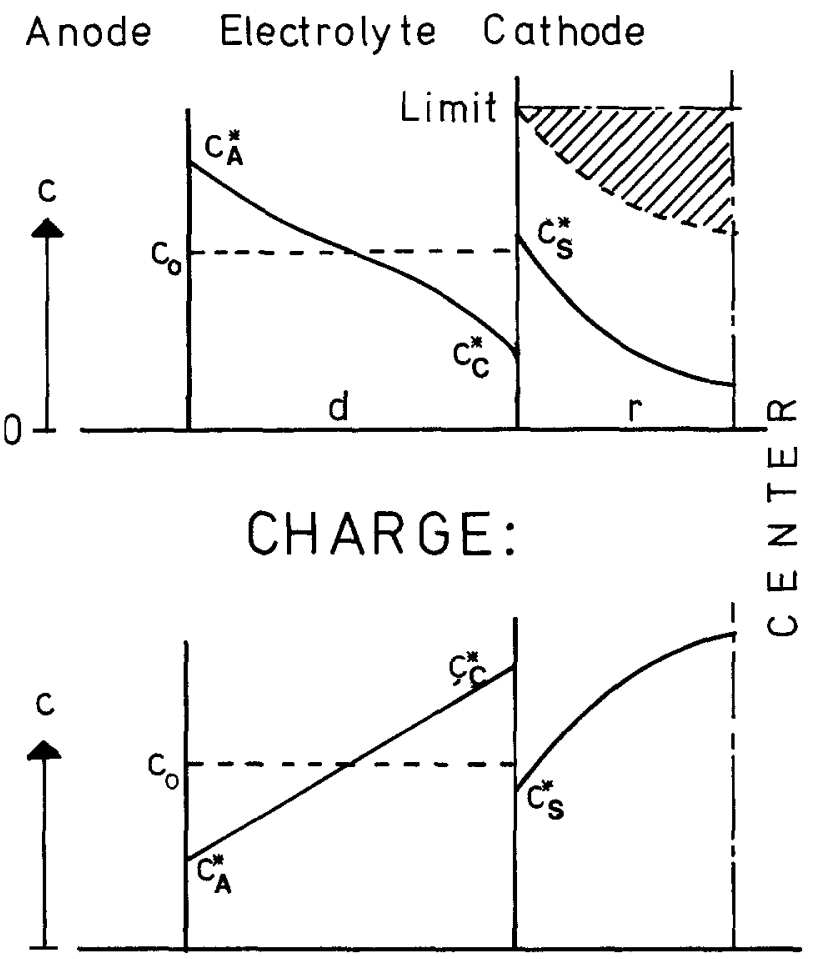

Fig. 1. Cation concentration profiles in electrolyte and solid solution cathode, $c_{\mathrm{A}}{ }^{*}, \mathrm{c}_{\mathrm{C}}{ }^{*}, \mathrm{cS}^{*}$ interfacial concentrations. $c_{0}$ initial concentration in electrolyte. .... profile at surface saturation. Hotched area: not utilized part of cathode.

In general these concentrations are functions of current density and time. However, a steady state will rapidly develop in the electrolyte accompanied by a linear concentration profile. In the cathode no steady state during load is possible. As long as the interfacial concentrations do not approach zero or their saturation values, their main effect is to sreate a transport overvoltage which reduces the working voltage of the battery. The contribution of $c_{\mathrm{A}}{ }^{*}$ and $c_{\mathrm{C}}{ }^{*}$ to this overvoltage can be estimated by a Nernst type of relation. As the current density during normal load is limited by the pulse load requirements (see later), the overvoltage plus the electrical potential loss across the electrolyte layer hardly exceeds $50 \mathrm{mV}$. (See Appendix A.)

The reversible cathode potential is determined by $c_{\mathrm{S}}{ }^{*}$. During discharge this concentration increases from its initial value near zero to a saturation value, where no more cations can be inserted.

This causes a decrease in cathode potential which for $\mathrm{Li} / \mathrm{TiS}_{2}$ is about $500 \mathrm{mV}$ (3). During discharge $c_{\mathrm{S}}{ }^{*}$ is higher than the equilibrium value, $c_{\mathrm{S}}$, which is determined by the total charge delivered by the battery.

Under the assumption that the transfer overvoltage is negligible, the rate dependent overvoltage is then determined by the difference $c_{\mathrm{S}}{ }^{*}-c_{\mathrm{S}}$. When $c_{\mathrm{S}}{ }^{*}$ is not too near the saturation value the total rate dependent overvoltage is, e.g., for $\mathrm{Li} / \mathrm{TiS}_{2}$ of the order of $200-300 \mathrm{mV}$. This decrease in battery voltage can generally be accepted without serious consequences. The time when the battery is completely discharged at the given load is therefore not determined by the overvoltages discussed above, but by the limiting situations which occur when $c_{\mathrm{C}}{ }^{*}$ approaches zero or $c_{\mathrm{S}}{ }^{*}$ its saturation value. In both cases the battery ceases to produce current at a useful voltage, and irreversible reactions at the electrodes may take place. 
These two limiting phenomena manifest themselves in different ways. In the electrolyte the time constant for diffusion is of the order of a few minutes. If the current density exceeds the limiting current $c_{\mathrm{C}}{ }^{*}$ attains a value near zero very fast, independent of the state of discharge. Thus this phenomenon works as a current limiter.

The situation where $c_{\mathrm{S}}{ }^{*}$ reaches its upper limit is depicted by the dotted line in Fig. 1. It is seen that an amount of cathodic material corresponding to the hatched area has not been utilized, even if the battery must be considered as completely discharged at the load in question.

The consequence is that the coulombic efficiency of the cathode has been reduced by an amount corresponding to the not utilized part of the cathode. This reduction can be considerable if the concentration gradient is steep and the electrode thickness large.

In the following the load on the battery is characterized by the stoichiometric discharge time, $T$, defined as

$$
T=\frac{\text { stoichiometric energy content }}{\text { average power required }}
$$

$T$ can be considered as a time constant characterizing the consumer battery system. $T$ is inversely proportional to the average discharge current which in the following is treated as constant; the influence of short intervals with a higher peak load is discussed later.

The time the battery has been under load, $t$, is transformed to the dimensionless variable, $\tau$, in relation to $T$

$$
\tau=\frac{t}{T}
$$

$\tau$ is then equal to the fraction of stoichiometric battery capacity used at time $t$, and the value of $\tau$ when $c_{\mathrm{S}}{ }^{*}$ reaches its saturation limit, $\tau^{*}$, is equal to the coulombic efficiency of the cathode.

In the following the concentration profiles as functions of $\tau$ and with the electrode thickness and $T$ as parameters are calculated. This is done by solving the diffusion equations for three different shapes of the cathode particles assuming constant current load.

\section{The Diffusion Model}

The model assumes that the cation and electron fluxes are uniformly distributed over the entire surface. This requires that the particles have a high electronic conductivity and form contacts with a metallic matrix serving as current collector. Even if these requirements can be met, the typical anisotropy of the ion transport in the layered structures used for solid solution cathodes, makes it questionable to what extent the assumption about uniform flux density is fulfilled.

The three particle shapes considered are: (i) an infinite plane sheet of thickness $2 r$ with both sides exposed to the electrolyte; (ii) infinitely long cylinders with radius $r$; and (iii) a number of spheres with radius $r$.

Starting with one mole of cathode material into which $n$ moles of cation can be inserted before saturation occurs, the total cation flux is $n / T$. With an average molar volume, $V_{m}$, of the host compound the surface areas, $S_{\mathrm{m}}$ and flux densities, $j_{\mathrm{o}}$, are

$$
\left.\begin{array}{lll}
\text { Plane sheet: } & S_{\mathrm{m}}=V_{\mathrm{m}} / r . & j_{\mathrm{o}}=\frac{n r}{T V_{\mathrm{m}}} \\
\text { Cylinders: } & S_{\mathrm{m}}=2 V_{\mathrm{m}} / r . & j_{0}=\frac{n r}{2 T V_{\mathrm{m}}} \\
\text { Spheres: } & S_{\mathrm{m}}=3 V_{\mathrm{m}} / r . & j_{0}=\frac{n r}{3 T V_{\mathrm{m}}}
\end{array}\right\}
$$

The transport is a coupled diffusion of cations and electrons. Under the assumption of high electronic conductivity, it can be described by the simple phenomenological equations

$$
j=-D \nabla(c) ; \quad \frac{\partial c}{\partial t}=D \nabla^{2}(c)
$$

where $c$ is the cation concentration and $j$ the flux. $D$ is a chemical diffusion coefficient which in general is composition dependent. However, very sparce information is available on this dependence and in the present work $D$ is treated as constant. Because of this approximation and because of the unsolved anisotropy problem, the following calculations can only be considered as semiquantitative.

In the present context solutions of [4] are desired for the case, where diffusion penetrates the entire cathode. Most discussions of [4] applied to electrode problems are limited to the semi-infinite case and short times (8) with the purpose of extracting the value of the diffusion coefficient. Mac Arthur (16) and van Buren et al. (17) have discussed solutions for the double-sided bounded domain, but with potentiostatic boundary conditions.

Scholtens and Broers (18), however, have treated the utilization of the cathode, based on solutions of [4] for the plane sheet. In the present work this treatment is extended and applied to the problem of cathode design.

The initial and boundary conditions for all three shapes are

$$
\begin{aligned}
& t=0 \quad \text { all } x \quad c=0 \\
& t>0 \quad x=r \quad \frac{d c}{d x}=-\frac{j_{0}}{D}
\end{aligned}
$$

For plane particles

$$
t>0 \quad x=0 \quad \frac{d c}{d x}=0
$$

For cylinders

For spheres

$$
t>0 \quad x \rightarrow 0 \quad 2 \pi x \frac{d c}{d x}=0
$$

$$
t>0 \quad x \rightarrow 0 \quad 4 \pi x^{2} \frac{d c}{d x}=0
$$

$-r<x<r$ is the space coordinate which in the cylindrical and spherical case is radial. The last boundary conditions express the symmetry about $x=$ 0 .

Solutions of the equivalent heat conduction problems for large values of $D t / r^{2}$ are given by Carslaw and Jaeger (19). Transformed to the diffusion case these solutions can be written in a general form

$$
\begin{aligned}
c(t, x)= & \frac{j_{0} r}{D}\left\{a \frac{D t}{r^{2}}+\frac{1}{2}\left(\frac{x}{r}\right)^{2}-b\right. \\
& \left.-2 \sum \frac{1 \exp -\frac{\alpha_{1}^{2} D t}{r^{2}}}{\alpha_{1}^{2}} c\left(\frac{\alpha_{1} x}{r}\right)\right\}
\end{aligned}
$$

where the $\alpha$ 's are the nonzero roots in the generating equations $g(\alpha)=0$, and the $C(\alpha z)$ 's are circular functions. $a$ and $b$ are constants, which together with the functions $C$ and $g$ are given in Table I including the

Table I. Constants and functions in Eq. [6]

\begin{tabular}{llllllll}
\hline Shape & $a$ & $b$ & $C(\alpha z)$ & $g(\alpha)$ & $\alpha_{1}$ & $\alpha_{2}$ & $\alpha_{s}$ \\
\hline Plane sheet & 1 & $1 / 6$ & $\cos \alpha z / \cos \alpha$ & $\sin \alpha$ & $\pi$ & $2 \pi$ & $3 \pi$ \\
Cylinders & 2 & $1 / 4$ & $J_{0}(\alpha z) / J_{0}(\alpha)$ & $J_{1}(\alpha)$ & 3.8317 & 7.0156 & 10.1735 \\
Spheres & 3 & $3 / 10$ & $\sin \alpha z / \sin \alpha$ & $\alpha \cot \alpha-1$ & 4.4934 & 7.7253 & 10.9041 \\
\hline
\end{tabular}

$J_{0}$ and $J_{1}$ are Bessel functions of first kind of order zero and 1. 
first three values of $\alpha_{\mathrm{i}}$. Introducing the dimensionless variables $\tau=t / T, z=x / r$ and the appropriate values for $j_{0}$, we get, e.g., for the plane sheet

$$
\begin{aligned}
c & =\frac{n}{V_{\mathrm{m}}} \tau+\frac{n r^{2}}{V_{\mathrm{m}} T D}\left(\frac{z^{2}}{2}-\frac{1}{6}\right. \\
& \left.-2 \sum^{1}\left[\frac{\exp \left(-\alpha_{1}{ }^{2} \frac{T D}{r^{2}} \tau\right)}{\alpha_{\mathrm{i}}{ }^{2}} \frac{\cos \left(\alpha_{\mathrm{i}} z\right)}{\cos \alpha_{\mathrm{i}}}\right]\right)
\end{aligned}
$$

The number of inserted cations per mole of host material is $c V_{\mathrm{m}} ; X(x, t)=c V_{\mathrm{m}} / n$ is then the local degree of discharge (utilization). The time constant for diffusion in a particle with thickness $r$ can be expressed as $r^{2} / D$. Thus the ratio $Q=T /\left(r^{2} / D\right)$ is a measure of how fast the transport in the cathode is compared to the required discharge rate expressed by the time constant $T$.

Inserting $X$ and $Q$ in [7] we get

$$
\begin{aligned}
X=\tau+ & \frac{1}{Q}\left(\frac{z^{2}}{2}-\frac{1}{6}\right. \\
& \left.-2 \sum^{3}\left[\frac{\exp \left(-\alpha_{i}^{2} Q \tau\right)}{\alpha_{i}^{2}} \frac{\cos \left(\alpha_{i} z\right)}{\cos \alpha_{i}}\right]\right)
\end{aligned}
$$

Similar expressions are obtained for cylinders and spheres. We are primarily interested in the surface value, $X^{*}$, which is obtained for $z=1$. The general expression for the three shapes is

$$
X^{*}=\tau+\frac{1}{A Q}\left[\frac{1}{B}-2 \sum^{1} \frac{\exp -\alpha_{\mathrm{i}}^{2} Q \tau}{\alpha_{\mathrm{i}}^{2}}\right]
$$

with the following values of the constants $A$ and $B$ :

$$
\text { Plane sheet }
$$

$$
\text { Cylinders }
$$

Spheres

$A$

$$
1
$$$$
2
$$$$
4
$$

It is remembered from the discussion above, that when $X^{*}$ attains the value 1 , the battery must be considered discharged. The corresponding value of $\tau=\tau^{*}$ is the coulombic efficiency of the cathode. This is for each particle shape a function of the characteristic parameter $Q$.

The expressions above have been formulated for the discharge process. They are easily modified for constant current charging. In this case $T$ is the time necessary to charge a completely discharged battery $(X=1)$. If the concentration at the start of charging is uniform corresponding to $X_{d}$ we have for $X^{*}$

$$
X^{*}=X_{\mathrm{d}}-\left\{\tau+\frac{1}{A Q}\left[\frac{1}{B}-2 \sum \frac{\exp -\alpha_{\mathrm{i}}^{2} Q \tau}{\alpha_{\mathrm{i}}^{2}}\right]\right\}
$$

In this case the critical value of $X^{*}$ is zero and the corresponding value of $\tau$ indicates the degree of charge obtained. However, more efficient charging procedures, e.g., constant potential charging, are available.

\section{Peak Power Requirements}

For many applications, e.g., vehicle propulsion, the battery is required to deliver typically 3-5 times more than the average power for very short periods, say $1-2 \%$ of $T$. Due to the linear properties of [4] the behavior under this additional load can be found as the sum of the necessary number of solutions satisfying the boundary conditions (20). If we assume that the battery has time to recuperate between successive peak periods, and that the energy consumption during peaks is incorporated in the average load figure, it is sufficient to consider one peak period at the end of discharge. If [9] is written $3 \mathrm{~s} X^{*}=G(Q, \tau)$ we get for $X_{p}{ }^{*}$ at the end of a peak period of length $\tau_{p}$

$$
X_{\mathrm{p}}{ }^{*}=G(Q \tau)+p G\left(Q \tau_{\mathrm{p}}\right)
$$

where $\tau$ corresponds to total time and $p$ is the additional load during peaks

$$
p=\frac{\text { peak power }}{\text { average power }}-1
$$

As the duration of the peak load is short, $\tau_{p}<0.02$, the solutions given in [9] converge too slowly, and short time expressions for the "peak part" of $X^{*}$ are required. These are based on the erfc and ierfc type of solution. For the plane sheet the solution is well known; Carslaw and Jaeger (21) have given an approximate solution for the cylirdrical case and for the spherical case a solution based on the Laplace transform is given in Appendix $B$. Introducing $Q, \tau_{p}$, and $p$ we get for the three particle shapes

$$
\begin{aligned}
\text { Plane sheet: } G\left(Q, \tau_{p}\right) & =2 \sqrt{\frac{\tau_{p}}{\pi Q}} \\
\text { Cylinders : } G\left(Q, \tau_{p}\right) & =\left(\sqrt{\frac{\tau_{p}}{\pi Q}+\frac{\tau_{p}}{4}}\right) \\
\text { Spheres }: G\left(Q, \tau_{p}\right) & =\left(\frac{2}{3} \sqrt{\frac{\tau_{p}}{\pi Q}+\frac{\tau_{p}}{3}}\right. \\
& \left.+\frac{4}{9} \sqrt{\frac{Q}{\pi} \tau_{p}^{3 / 2}}\right)
\end{aligned}
$$

The precision of these expressions is better than $2 \%$ for $Q \tau_{p}<0.1$.

\section{Results}

Results are given as sets of curves illustrating typical relations between $X, X^{*}, \tau, \tau^{*}$, and $Q$.

Figure 2 shows concentration profiles in the plane sheet and in equivalent spheres for $Q=1$ at different values of $\tau$. For larger values of $Q$ the distribution gets more uniform. For $\tau<0.05$ the diffusion is virtually semi-infinite.

The cathode behavior during discharge is illustrated by graphs showing $X^{*}$ as a function of $\tau$ with $Q$ and particle shape as parameters. A set of such curves is presented in Fig. 3. As the cathode potential under the assumption of thermodynamic reversibility is a function of $X^{*}$ alone, the $X^{*}, \tau$ graphs can be transformed into "discharge curves" showing the decline of the cathode potential with discharge time. In some cases a modified Nernst equation can be used, in other cases, e.g., for the $\mathrm{Li} / \mathrm{TiS}_{2}$ couple, a linear relation appears to be a good approximation $(3,22)$. However, in all cases the cathode potential declines steeply as $X^{*}$ approaches 1 .

The $X^{*}, \tau$ curves can also be used to find the rate dependent "overconcentration" corresponding to the cathodic overvoltage. The overconcentration is the difference between the dotted line with slope 1 and the $X^{*}, \tau$ curve.

For small values of $Q \tau$ the curves are parabolic in shape, whereas for $Q \tau>0.3$ for the plane sheet and correspondingly less for cylinders and spheres the curves approach linearity with slope 1 (18). This is a consequence of the linear $\tau$ term in [9] dominating over the vanishing exponential terms divided by $Q$.

The relation between the coulombic efficiency $\tau^{*}$ and $Q$ gives the dependence of specific energy on power requirements and cathode parameters. This relation is obtained by equating $X^{*}$ to 1 and solving 


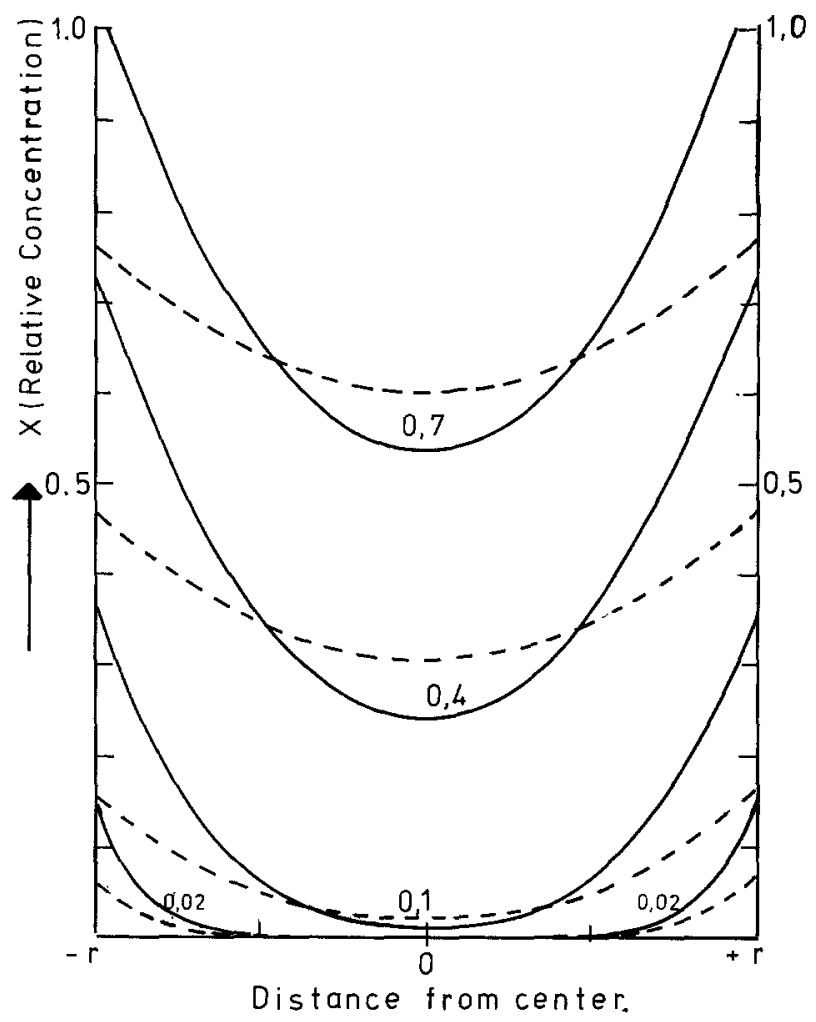

Fig. 2. Concentration profiles in particle for $Q=1$ and different volues of $\tau$ os indicated on graphs. ___ plane sheet. ...... spherical porticle.

for $\tau^{*}$. For constant load the coulombic efficiency is plotted as a function of $\log Q$ in Fig. 4 .

The peak load level and the peak length will form a complicated pattern. For the purpose of determining the end discharge a typical peak length and the typical ratio between peak and normal load is sufficient. For traction purposes the peak will last between 30 sec and some minutes, corresponding to acceleration and hill climbing, respectively. As the total discharge time, $T$, for this purpose is between $1.5-3 \mathrm{hr}$, the peak length will be $0.5-1 \%$ of $T$, i.e., $\tau_{p}$ is $0.005-0.01$. The desired peak power is estimated to 3-5 times the average power, corresponding to $p$ ranging from 2 to 4 .

To illustrate the significance of these requirements, $\tau^{*}, \log Q$ curves for the four different peak load conditions compared with average load are shown in

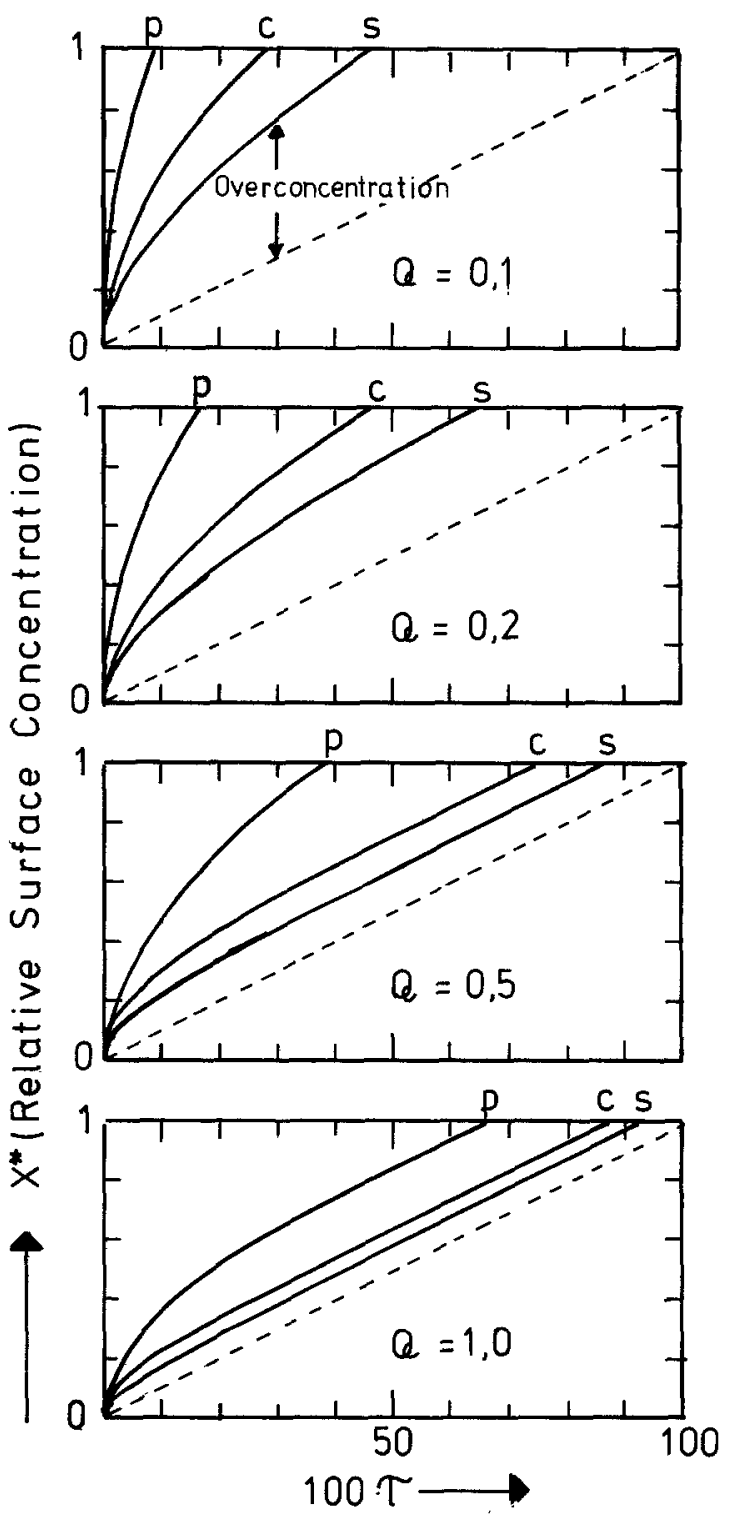

Fig. 3. Relotive surface concentration $X^{*}$ as function of $\tau$ for different values of $Q$ as indicated. $p$ : plane, $c$ : cylindrical and s: spherical particles. Dotted line: equilibrium value for $X^{*}$.

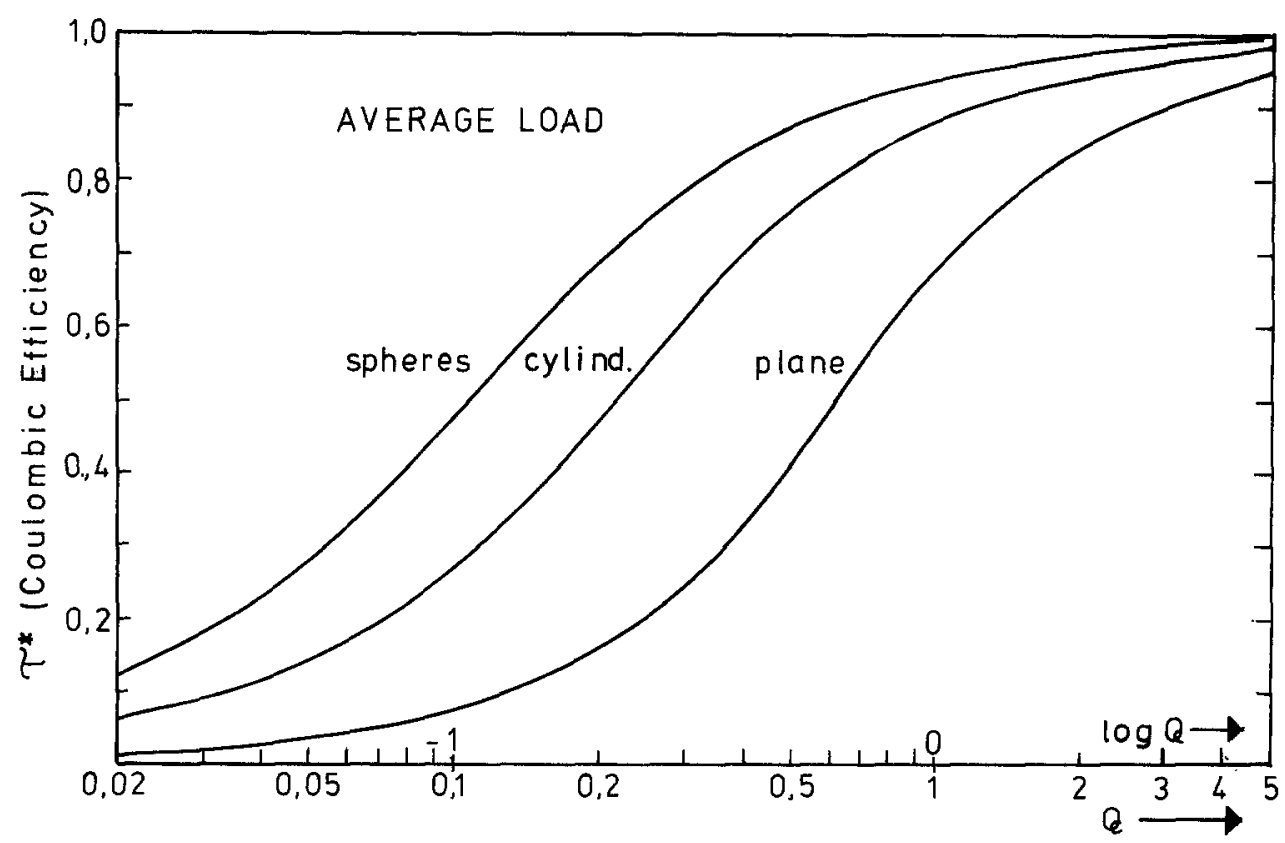

Fig. 4. Cathode efficiency (cathode utilization of $X^{*}=1$ ) as function of $\log Q$. Average load with no peak loading. Particle shape indicated on grophs. 
Fig. 5. The cylindrical particle shape was used as this is intermediate between plane and spherical particles. The influence of the peak load is considerable. For $Q<0.4$ the coulombic efficiency is more than halved by the heaviest peak load.

This reduction of battery capacity as the load, i.e., the current, is momentarily increased, is often ascribed to the "internal resistance" in the battery. However, it is clear from the above discussion that this has nothing to do with the ohmic resistance components as determined, e.g., by a-c measurements.

The $Q, \tau^{*}$ graphs for the different particle shapes for 3 times peak load and peak length $1 \%$ of $T$ are shown in Fig. 6.

\section{Transport Limitations in the Electrolyte}

The electrolytic cation transport is related to the current density calculated on the basis of projected area of the cathode. For cylinders and spheres this current is different from the expressions given in [3].

Assuming that the cathode is made from one layer of particles, that cylindrical particles are arranged with their axes perpendicular to the current, and that spheres are hexagonally closed packed, the projected average current densities, $i_{\mathrm{a}}$, are

$$
i_{\mathrm{a}}=f \frac{n \mathbf{F} r}{V_{\mathrm{m}} T}
$$

where for the plane electrode $f=1$, for cylinders $f=\pi / 4$, and for spheres $f=\pi / 3 \sqrt{3}$.

In Appendix $A$ the cation concentration profiles for two plane electrodes spaced a distance $d$ apart are calculated for the steady-state situation. A limiting current $i_{\mathrm{C}}{ }^{*}$ occurs for $c_{\mathrm{C}}{ }^{*}=0$

$$
i_{\mathrm{C}} *=\frac{4 F c_{0} D_{+}}{d}
$$

where $c_{o}$ is the cation concentration in the electrolyte, $D_{+}$the cation diffusion coefficient.

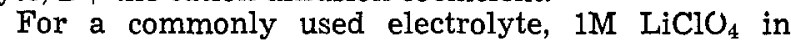
propylenecarbonate, $D_{+}$is estimated to be $1.310^{-6} \mathrm{~cm}^{2}$ $\mathrm{sec}^{-1}$ at $25^{\circ} \mathrm{C}, 1$ and a usual value for $d$ is $0.03 \mathrm{~cm}$. This gives $i_{\mathrm{C}}{ }^{*}=17 \mathrm{~mA} \mathrm{~cm}-2$. The time constant for the nonsteady-state diffusion is in the present case $d^{2} / 8 t_{-} D_{+}$. The above data give a value of about 3.5 min, i.e., the same order of magnitude as the peak

1 This figure was arrived at by combining chronopotentiometric measurements by Gabano $(23)$ at $15^{\circ} \mathrm{C}$ with the figure for $D_{0}=$ $3.410^{-6} \mathrm{~cm}^{2}$ sec $^{-1}$ given by Jasinski (24)
Fig. 5. Cothode efficiency for cylindrical particles as function of $\log Q$. Averoge and different peak loads. $p=$ (peak/overage power -1 ) indicated on grophs. $\cdots \tau_{p}=0.005$. $\tau_{p}=$ 0.01 .

Fig. 6. Cothode efficiency for average + peak load, $p=2$ $\tau_{p}=0.01$, os function of $\log Q$. Particle shape indicated on graphs.
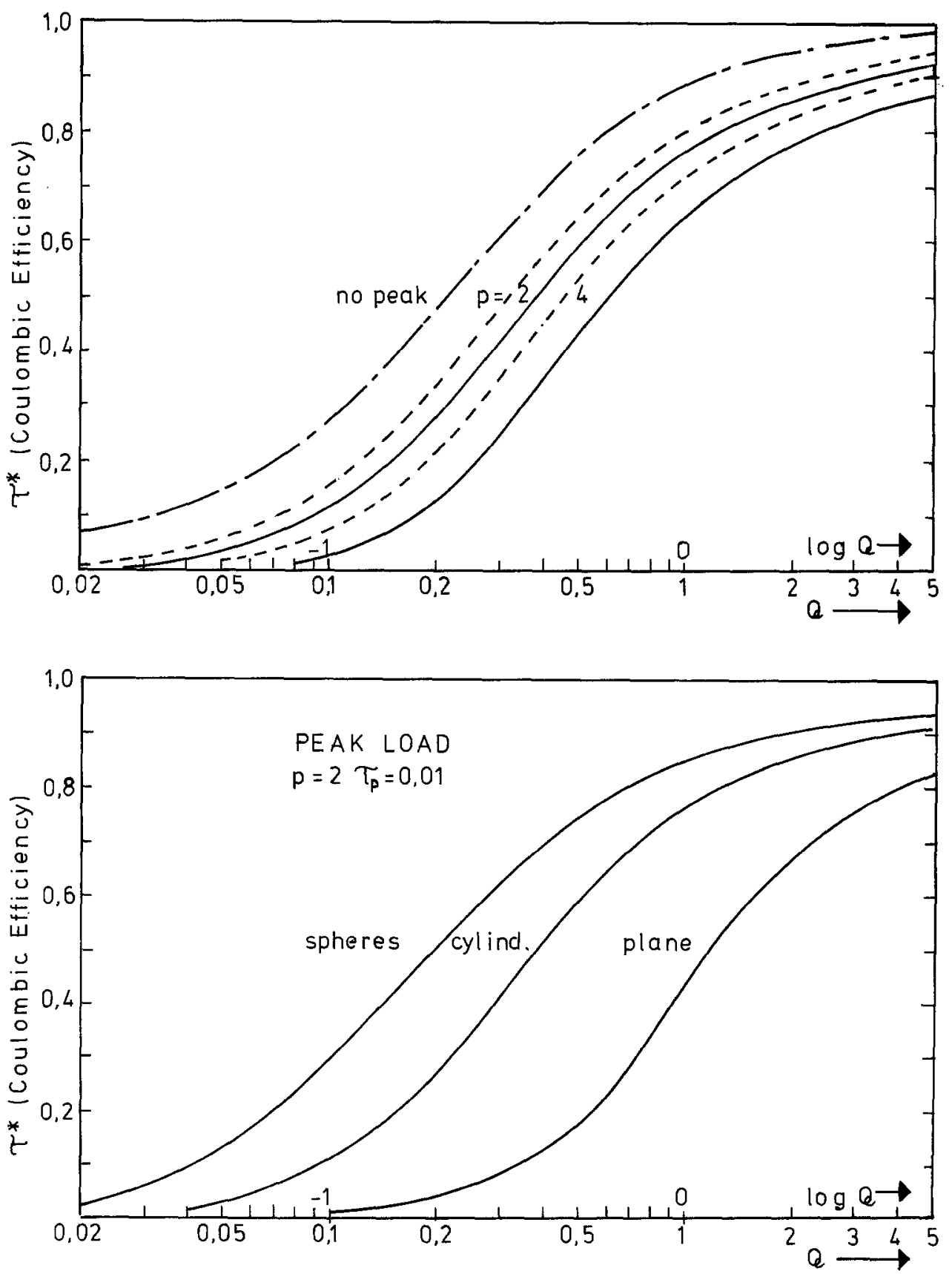
periods. The steady-state limiting current therefore is used for peak load conditions. Thus to avoid current limitation during peaks, the peak current density, $(p+1) i_{\mathrm{a}}$ must be kept smaller than $i_{\mathrm{C}}{ }^{*}$. Combining [14] and [15] an upper limit for the product $r \cdot d$, dependent on $T$ and the electrolyte and cathode properties, is

$$
r \cdot d<T \frac{4 c_{o} V_{m} D_{+}}{(p+1) f n}
$$

For a plane cathode of $\operatorname{TiS}_{2}\left(V_{\mathrm{m}}=35, n=1\right)$, the above electrolyte, $T=2 \mathrm{hr}$ and 3 times peak load, Eq. [16] gives $r \cdot d<(0.036)^{2} \mathrm{~cm}^{2}$. Strictly [16] is only valid for plane electrodes. For $d>r$ it gives a reasonable approximation for single layers of cylinders and spheres. For porous electrodes, $(m>1)$, Eq. [16] holds qualitatively as discussed later.

Equation [16] and the relation between $Q$ and cathode efficiency given in Fig. 5-6 allow an estimate of an optimized compromise for the dimensions of the cathode and electrolyte layer.

\section{Discussion}

For a given application, the cost and weight of the battery is proportional to $T$. System designers will therefore choose the lowest value for $T$ which satisfies consumer requirements. $T$ can range from several years for heart pacemakers to minutes for military applications.

The discharge rate, however, is inversely proportional to $T$. A low value of $T$ can consequently limit the specific energy of the battery depending on the rate capabilities of the electrochemical system.

To demonstrate this, the results obtained in the preceding sections are applied to the $\mathrm{Li} / \mathrm{TiS}_{2}$ couple with the propylene-carbonate- $\mathrm{LiClO}_{4}$ electrolyte.

In these considerations the parameter $Q$ has a central place. It appears therefore reasonable to summarize the different magnitudes entering in the expression for $Q$

$$
Q=\frac{T D}{r^{2}}=\frac{n \mathbf{F} D}{I r^{2}}=\frac{n \mathbf{F} D}{a i V_{\mathrm{m}} r}
$$

where $I$ is the current per mole host compound, $i$ the current density per unit particle surface area, and $a$ the shape parameter from Table I.

The data for the $\mathrm{Li} / \mathrm{TiS}_{2}$ couple used in the following are

$$
\text { Cathode }
$$

Molecular weight:

Molecular volume:

Electronic conductivity:

Diffusion coefficient for $\mathrm{Li}$ :

$210^{-8}$

Voltage range:

Specific stoichiometric energy:

The value given for $D$, the diffusion coefficient for $\mathrm{Li}$ in $\mathrm{Li}_{x} \mathrm{TiS}_{2}$, needs some comments. $D$ was determined at $x=0.5$ by an electrochemical method. In the calculations it was assumed that only the area corresponding to diffusion perpendicular to the $c$ axis was active (25). The average value will therefore be lower, and a value of $10^{-8} \mathrm{~cm}^{2} \mathrm{sec}^{-1}$ is used in the following calculations.

As mentioned before vehicle propulsion is an important field for advanced batteries and as an example the $\mathrm{Li} / \mathrm{TiS}_{2}$ system is discussed in relation to this application. Typical for this area is emphasis on low weight and good peak load performance.

The aim for electric cars in the near-time future is an average speed of $60 \mathrm{~km} / \mathrm{hr}$ with a range between charges of $100-150 \mathrm{~km}$. This gives a value for $T$ of 2-3 $\mathrm{hr}$ which is near the standard for testing lead acid batteries for this purpose. Two hours is used in the following and the peak power is estimated to three times average load $(p=2)$ with a peak length of $0.01 T$.
With plane cathodes or cathodes consisting of a single layer of cylindrical or spherical particles the cathode efficiency is determined by the electrode or particle thickness, 2r. Existing technology (sintered plate $\mathrm{Ni} / \mathrm{Cd}$ batteries) employs electrode thicknesses down to $0.05 \mathrm{~cm}(r=0.025)$. With $D=10^{-8} \mathrm{~cm}^{2}$ $\sec ^{-1}$ and $T=2 \mathrm{hr}, Q$ is then 0.1 . From Fig. 6 it is seen that with this value of $Q$ a plane electrode has very little capacity, whereas cylindrical and spherical particles give 11 and $29 \%$ cathodic efficiency.

Generally such low efficiencies cannot be accepted. Moreover application of [16] shows that with an electrolyte thickness of $0.03 \mathrm{~cm}$ the current density in the electrolyte during peak periods approaches the critical limiting current density. ${ }^{2}$ Obviously the electrode or particle thickness must be reduced in order to improve as well the cathodic efficiency as the peak load behavior. A possible approach is to use a film electrode carried on a thin current collector. An efficiency of $80 \%$ requires $Q=4$ for a plane electrode which gives $r=43 \mu \mathrm{m}$ and a corresponding thickness of a $\mathrm{Li}$ anode of $20 \mu \mathrm{m}$. As, however, the thickness of current collector + electrolyte layer hardly can be kept below 250-300 $\mu \mathrm{m}$, the weight of the active components, $\mathrm{Li}$ and $\mathrm{TiS}_{2}$, only amounts to a small part of the total weight resulting in a very low "packaging efficiency." In Appendix $\mathrm{C}$ the packaging efficiency is discussed on the basis of the simple models for battery design shown in Fig. 7, and for the film electrode this efficiency is estimated to about $20 \%$. All in all the result is a specific energy of about $70 \mathrm{~W}-\mathrm{hr} / \mathrm{kg}$, only $15 \%$ of the stoichiometric value.

A cathodic efficiency of $80 \%$ can also be obtained with spherical particles with $r=100 \mu \mathrm{m}(Q=0.7)$. Technologically these appear easier to handle, but due to the shape, the packaging is also in this case bad, and the resulting specific energy is estimated to be $80 \mathrm{~W}-\mathrm{hr} / \mathrm{kg}$.

If the particle size is increased further to improve the packaging efficiency, $Q$ is decreased and the cathodic efficiency falls off drastically. The figures mentioned above appear to be near the limit for this type of electrodes. The specific energy densities which are obtained, $70-80 \mathrm{~W}-\mathrm{hr} / \mathrm{kg}$, do not appear very attractive compared with what is expected from improved versions of lead-acid, $\mathrm{Ni} / \mathrm{Zn}$, and other systems.

\section{Anode}

$7 \mathrm{~g} \mathrm{~mol}^{-1}$

$13 \mathrm{~cm}^{3} \mathrm{~mol}^{-1}$

$-\mathrm{cm}^{2} \mathrm{sec}^{-1}(22)$

$2.4-1.9 \mathrm{~V}(22)$

$480 \mathrm{~W}-\mathrm{hr} / \mathrm{kg}$

A material with a higher value for the diffusion coefficient than $10^{-8} \mathrm{~cm}^{2} \mathrm{sec}^{-1}$ would permit use of larger particles, but for batteries with organic electrolytes the particle size is also limited by the requirements expressed in [16], and an improvement of the packaging can generally not be obtained without a higher diffusion coefficient for $\mathrm{Li}^{+}$in the electrolyte.

At less severe loads, e.g., for $T$ larger than $5 \mathrm{hr}$ and no peak load requirements, much better results can be expected from systems like the $\mathrm{Li} / \mathrm{TiS}_{2}$. Specific energies in the range of $120-150 \mathrm{~W}-\mathrm{hr} / \mathrm{kg}$ can probably be obtained even from plane electrodes about $0.02 \mathrm{~cm}$ in thickness.

To improve the performance on heavy loads Scholten (18) has proposed the use of porous cathodes and treated some of the problems in this connection. An

short circuits in high energy density batteries represent a serious safety risk and it is noc advisable to reduce the electrolyte layer thickness except in cases where a dense separator is used. Due to tortuosity and the restricted cross-section area in the separator, this does usually not improve the limiting current. 


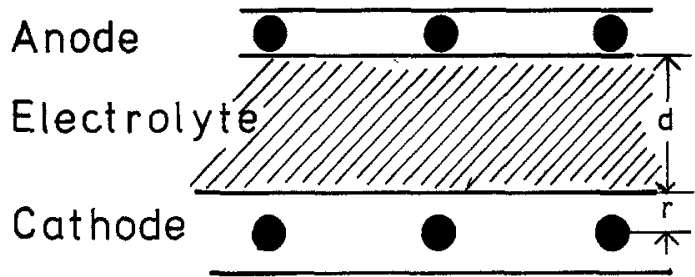

Plane Cathode
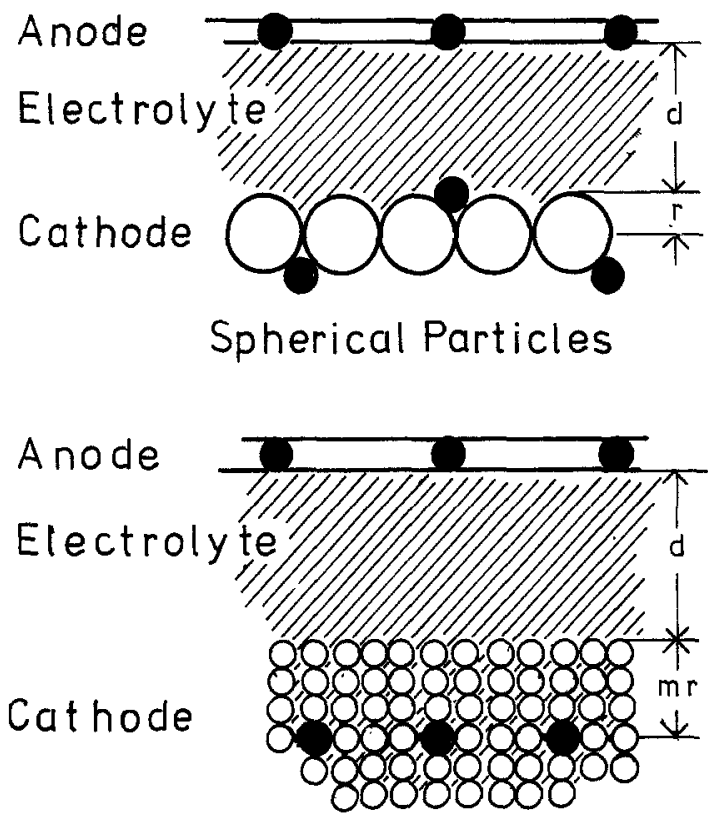

Porous Structure

\section{Current Collector}

Fig. 7. Models of battery configurations for estimating "packoging efficiency."

exact evaluation of the advantages of porous electrodes is outside the scope of this paper, but a short qualitative discussion appears appropriate. For this purpose it is convenient to consider the porous electrode as consisting of $m$ layers of spherical particles arranged in a cubic packing as depicted in Fig. 7. This model presumes that the cathode material, like $\mathrm{TiS}_{2}$, has a very good electronic conductivity. If not, a conductive material such as graphite must be added, thus lowering the specific energy. In case of an electrode with a high porosity, the current distribution in the pores will tend to be uniform as long as the overvoltage is large compared to the electrical potential gradient in the pores. For the systems considered here this condition is fulfilled, as long as the cation concentration in the pores does not approach zero.

This means that we can estimate the total cathodic efficiency from $Q$, calculated for the single particles. Consequently by choosing a small value for $r$, high efficiencies can be obtained. Even with $D$ as low as $10^{-10} \mathrm{~cm}^{2} \mathrm{sec}^{-1}$ a value of $2.5 \mu \mathrm{m}$ for $r$ ensures an efficiency above $90 \%$.

The packaging efficiency is determined by the total cathode thickness $m \cdot r$, and by the porosity. For large values of $m \cdot r$ packaging efficiencies in the range of $60-70 \%$ can be obtained.

The limit for the specific energy is, however, set by the cation transport in the electrolyte. To ensure that the entire cathode is active, the cation concentration even at the bottom of the pores should not approach zero. Equation [16] consequently is modified to

$$
r(d+m \cdot r)<T \frac{4 c_{o} V_{m} D_{+}}{n(p+1) f}
$$

where $f$ for cubic packed spheres is $\pi / 6$.

The term $d+m \cdot r$ requires some comments. In the derivation of [16] it was assumed that the cation flux density in the electrolyte was uniform. In the pores, however, the cation flux decreases to zero at the bottom of the pores. In this respect the term $d+$ $m \cdot r$ is overestimated. On the other hand the flux density at the openings of the pores is considerably larger than in the electrolyte due to the smaller crosssection area in the pores. It is assumed that these two effects approximately cancel.

As an example assume $r=25 \mu \mathrm{m}$ for spherical particles. $Q$ is then 11 and the cathodic efficiency $95 \%$. With the electrolyte thickness $d=0.03 \mathrm{~cm}$ we get from [17] a maximal value for the cathode thickness, $2 m r$ of $0.035 \mathrm{~cm}$, and the specific energy is then estimated to be about $120 \mathrm{~W}-\mathrm{hr} / \mathrm{kg}$. Without peak load $(p=0)$ we arrive at a cathode thickness of about $0.075 \mathrm{~cm}$ and a specific energy of $180 \mathrm{~W}-\mathrm{hr} / \mathrm{kg}$.

The figures calculated above can for several reasons only serve as examples, demonstrating the application of the principles discussed in this work. It is, however, worth noticing that for the $\mathrm{Li} / \mathrm{TiS}_{2}$ couple discussed here, the practically obtained energy density is quoted as $134 \mathrm{~W}-\mathrm{hr} / \mathrm{kg}$ at the $1-6 \mathrm{hr}$ discharge rate $(26)$.

\section{Conclusion}

The description of the properties of solid solution cathodes used with an alkali metal anode can be based on the presumption that the available energy content of a battery with such electrodes is limited by saturation of the cathode surface with cations. The ratio between the time constant for the battery under load, i.e., the stoichiometric discharge time $T$, and the time constant for diffusion in the solid solution particles form a parameter, $Q$, which together with the shape of the particles fully describes the behavior of the cathode particles under a constant current load. Peak loads can be included in this description by specifying the peak length and the ratio between peak and average load.

The cathode efficiency, i.e., the utilization of the cathode at the end of discharge, is heavily dependent on $Q$. To obtain a cathode efficiency of 0.8 or more, $Q$ should be larger than 0.4 for spherical particles and 2 for plane electrodes. Peak loads exert a considerable influence on these figures in particular for plane electrodes.

For loads relevant to batteries for vehicle propulsion the particle size necessary to obtain an acceptable value for $Q$ is so small that single layer or film electrodes are out of the question because of a low "packaging efficiency" and technological limitations. This is under the assumption of solid-state diffusion coefficients for the cation in the range of $10^{-8} \mathrm{~cm}^{2}$ $\mathrm{sec}^{-1}$. For porous cathodes a high value of $Q$ can be obtained even in the case of considerably smaller values for the diffusion coefficient. However, in this case the transport of the cation in the electrolyte limits the thickness of the cathode and thereby the "packaging efficiency" and technological limitations. the battery.

Although the discussion of these phenomena has been based on rather crude approximations, estimates based on the $\mathrm{Li}^{+}$mobility in propylenecarbonate electrolyte show, that for porous electrodes a reduction in the stoichiometric specific energy by a factor of 4 may be expected for loads corresponding to vehicle propulsion requirements. For less severe loads the reduction factor will be near to 3 .

Even with this background, the solid solution cathode systems, as exemplified by the $\mathrm{Li} / \mathrm{TiS}_{2}$ couple, compare favorably with conventional and some other 
advanced battery systems. In relation to the $\mathrm{Na} / \mathrm{S}$ system the alkali metal/solid solution systems, operated at ambient temperature, cannot compete with regard to specific energy content, but they possess great principle and safety advantages.

\section{Acknowledgments}

The authors wish to acknowledge the inspiration gained from discussions with colleagues participating in the joint British-Danish Energy Research Programme (contracts 315, 316-78 EE-DK, UK) and the financial support to one of us (K. West) from the Danish Council for Technical Scientific Research.

Manuscript submitted Oct. 17, 1978; revised manuscript received Jan. 23, 1979.

Any discussion of this paper will appear in a Discussion Section to be published in the June 1980 Journal. All discussions for the June 1980 Discussion Section should be submitted by Feb. 1, 1980.

\section{APPENDIX A}

The initial and boundary condition for cation transport with current density " $i$ " in an electrolyte layer of thickness $d$ is

$$
\begin{gathered}
t<0, \quad-\frac{d}{2} \leq x \leq \frac{d}{2} \quad c(x)=c_{0} \\
t>0, \quad x= \pm \frac{d}{2}, \quad j_{+}=\frac{i}{z_{+} \mathbf{F}}, \quad j_{-}=0
\end{gathered}
$$

and for symmetry reasons

$$
x=0, c=c_{o}
$$

The time constant for diffusion is $d^{2} / 8 t-D_{+}$in the order of some minutes. At larger discharge times the transport is described by steady-state conditions

$$
\begin{gathered}
j_{-}=0=>d \bar{\mu}_{-}=0 \\
j_{+}=\frac{i}{z_{+} \mathbf{F}}=-D_{+} \frac{d c_{+}}{d x}-z_{+} \mathbf{F} \frac{D_{+}}{R T} c_{+} \frac{d \phi}{d x}
\end{gathered}
$$

where $D_{+}$is cation diffusion coefficient.

For a 1,1 electrolyte $\left(\mathrm{LiClO}_{4}\right)[\mathrm{A}-4]$ gives

$$
c=c_{+}=c_{-}, \frac{d \phi}{d x}=\frac{R T}{F} \frac{d \ln c}{d x}
$$

under the assumption of constant activity coefficients. Thus from $[\mathrm{A}-5]$ and $[\mathrm{A}-2]$

$$
\frac{i}{\mathbf{F}}=-2 D+\frac{d c}{d x}
$$

and from $[\mathrm{A}-3]$ the interfacial concentrations

$$
\begin{aligned}
& c_{A}{ }^{*}=c_{o}+\frac{i d}{4 F D_{+}} \\
& c_{C}{ }^{*}=c_{0}-\frac{i d}{4 F D_{+}}
\end{aligned}
$$

$c_{\mathrm{C}}{ }^{*}=0$ gives the limiting current

$$
i_{\mathrm{C}}^{*}=\frac{4 \mathrm{~F} c_{0} D_{+}}{d}
$$

Integration of [A-6] gives

$$
\Delta \phi=\frac{R T}{\mathbf{F}} \ln \frac{c_{\mathrm{A}}^{*}}{c_{\mathrm{C}}{ }^{*}}
$$

which is sometimes confused with an "ohmic potential loss."

The concentration (Nernst) overvoltage is

$$
\eta_{\mathrm{c}}=\frac{R T}{\mathrm{~F}} \ln \frac{c_{\mathrm{A}}^{*}}{c_{\mathrm{C}}{ }^{*}}
$$

The total potential difference due to transport across the electrolyte is

$$
\eta=\eta_{c}+\Delta \phi=\frac{2 R T}{F} \ln \frac{c_{A}^{*}}{c_{C}{ }^{*}}
$$

If $i=i_{\mathrm{C}} * / 3$ corresponding to average current when peak current $=i_{\mathrm{C}}{ }^{*},[\mathrm{~A}-12]$ gives $\eta=0.036 \mathrm{~V}$.

\section{APPENDIX B}

Short time solution for spherical diffusion with constant flux density at the surface can be obtained thus: The expression for radial diffusion in a sphere can be written

$$
\frac{\partial c}{\partial t}=D\left(\frac{\partial^{2} c}{\partial x^{2}}+\frac{2}{x} \frac{\partial c}{\partial x}\right) \quad 0<x \leqslant r
$$

Using the substitution $z=x \cdot c$ and taking the Laplace transiorm $L\{c(t, x)\}=u(s, x)$

$$
\frac{\partial^{2}(u \cdot x)}{\partial x^{2}}-\frac{S}{D}(u \cdot x)=0
$$

With the solution

$$
u \cdot x=A \exp -\sqrt{\frac{s}{D}} \cdot x+B \exp \sqrt{\frac{s}{D}} \cdot x[\mathrm{~B}-3]
$$

Using the boundary condition $\lim _{x \rightarrow 0} 4 \pi x^{2} \frac{d c}{d x}=0, A=$ $-B$, so

The other boundary condition is

$$
u=2 \frac{A}{x} \sinh \sqrt{\frac{s}{D}} \cdot x
$$

$$
x=r, \quad \frac{d c}{d x}=-\frac{j_{0}}{D}=>\frac{d u}{d x}=-\frac{j_{0}}{s D}
$$

Inserted in [B-4] gives for $x=r$

$$
u(s, r)=\frac{j_{0} r}{D} \frac{1}{s} \frac{1}{1+\frac{r}{\sqrt{D}} \sqrt{s} \operatorname{coth}\left(\sqrt{\frac{s}{D} \cdot r}\right)}
$$

For small $t$ only large $s$ gives a contribution to the transform. Thus

$$
\begin{aligned}
t \rightarrow 0 \quad \operatorname{coth}\left(\sqrt{\frac{s}{D}} \cdot r\right) & \rightarrow 1 \text { and } \\
u(s, r) & =\frac{j_{0} r}{D} \frac{1}{s} \frac{1}{1+\frac{r}{D} \sqrt{s}}
\end{aligned}
$$

Use of partial fractions and inverse transformation from standard tables gives

$c^{*}(x=r)=\frac{j_{\mathrm{o}} r}{D}\left(1-\exp \left(\frac{D t}{r^{2}}\right) \operatorname{erfc} \sqrt{\frac{D t}{r^{2}}}\right)$

For the peak period $t_{\mathrm{p}}$ and with peak load $(p+1)$ times average load we have (see [3])

$$
j_{\mathrm{o}, \mathrm{p}}=p \frac{n r}{3 T V_{\mathrm{m}}} ; \quad \tau_{\mathrm{p}}=\frac{t_{\mathrm{p}}}{T}
$$

where $T$ refers to average load and $j_{0, p}$ to the additional flux during peaks. Inserting $[B-9]$ and $Q=I D / r^{2}$ in $[\mathrm{B}-8]$

$$
X_{p}=\frac{p}{3 Q}\left(1-\exp \left(Q \tau_{p}\right) \cdot \operatorname{erfc} \sqrt{Q \tau_{p}}\right)
$$

and expanding exp and erfc

$$
X_{\mathrm{p}}=p\left(\frac{2}{3} \sqrt{\frac{\tau_{\mathrm{p}}}{\pi Q}}+\frac{\tau_{\mathrm{p}}}{3}+\frac{4}{9} \sqrt{\frac{Q}{\pi}} \tau_{\mathrm{p}}{ }^{3 / 2}\right)
$$
where $X_{D}$ is the concentration increase due to the peak. 
Toble II.

\begin{tabular}{|c|c|c|c|c|c|c|}
\hline $\begin{array}{l}m \cdot r \\
d \\
\text { Shape } \\
\text { Cathodic efficiency }\end{array}$ & $\underset{\mathrm{cm}}{\mathrm{cm}}$ & $\begin{array}{l}0.025 \\
0.030 \\
\text { Spheres } \\
0.29\end{array}$ & $\begin{array}{l}0.0043 \\
0.025 \\
\text { Plane } \\
0.80\end{array}$ & $\begin{array}{l}0.01 \\
0.03 \\
\text { Spheres } \\
0.80\end{array}$ & $\begin{array}{l}7 \cdot 0.0025 \\
0.03 \\
\text { Porous } \\
0.95\end{array}$ & $\begin{array}{l}15 \cdot 0.0025 \\
0.03 \\
\text { Porous } \\
0.95\end{array}$ \\
\hline \multicolumn{7}{|l|}{ Weight of: } \\
\hline $\begin{array}{l}\text { Cathode } \\
\text { Anode } \\
\text { Electrolyte layer } \\
\text { Electronyte in "pores" } \\
\text { Current coliector } \\
\text { Packaging elficiency } \\
\text { Specific energy }\end{array}$ & $\begin{array}{l}\mathrm{g} / \mathbf{c m}^{2} \\
\mathrm{~g} / \mathbf{c m}^{2} \\
\mathrm{~g} / \mathrm{cm}^{2} \\
\mathrm{~g} / \mathrm{cm}^{2} \\
\mathrm{~g} / \mathrm{cm}^{2} \\
\text { W-hr/kg }\end{array}$ & $\begin{array}{l}0.0483 \\
0.0030 \\
0.0360 \\
0.0072 \\
0.0174 \\
0.41 \\
\mathbf{5 2}\end{array}$ & $\begin{array}{l}0.0138 \\
0.0009 \\
0.0300 \\
\overline{0.0174} \\
0.21 \\
74\end{array}$ & $\begin{array}{l}0.0193 \\
0.0012 \\
0.0360 \\
0.0050 \\
0.0174 \\
0.23 \\
80\end{array}$ & $\begin{array}{r}0.0293 \\
0.0018 \\
0.0360 \\
0.0100 \\
0.0174 \\
0.33 \\
121\end{array}$ & $\begin{array}{r}0.0628 \\
0.0040 \\
0.0360 \\
0.0215 \\
0.0174 \\
0.47 \\
174\end{array}$ \\
\hline
\end{tabular}

APPENDIX C

The specific energy obtained from a practical battery can be estimated as a product of stoichiometric speciric energy, cathode efficiency, correction tor overvoltage, and "packing efficiency," which is the fraction of total battery weignt used for active materials.

Using a simple flat electrode configuration (Fig. 7) and knowing cathode and electrolyte thickness and densities the packaging etficiency can be estimated. Assumptions must be made about the weight of the current collector and the weignt of battery container, terminals, etc. The container, etc., is estimated to $10 \%$ of battery weight as for the lead-acid cell.

As the cathode materials discussed here are supposed to have high electronic conductivity, the primary role of the cathode current collector is to support the cathode, be it a flat plate or an agglomerate of cylinders or spheres. A 10 mesh nickel net with $0.005 \mathrm{~cm}$ wire diameter is supposed to serve this purpose. It has a weight of $0.0174 \mathrm{~g} \mathrm{~cm}^{-2}$. The same net is used for the anode.

For single layer spherical particles the amount of electrolyte must be increased by the electrolyte between spheres ( $40 \%$ of normal cathode volume) and for porous electrodes consisting of cubic packed spheres with $48 \%$ of cathode volume.

In Table II the different weignt components for the exampies discussed in the main text are shown. The density for the electrolyte is set to $1.2 \mathrm{~g} \mathrm{~cm}^{-3}$ and for $\mathrm{TiS}_{2}$ to $3.2 \mathrm{~g} \mathrm{~cm}^{-3}$. The stoichiometric specific energp for ' $\mathrm{IiS}_{2}$ is $480 \mathrm{~W}-\mathrm{hr} / \mathrm{kg}$ and the overvoltage correction 0.9 .

\section{$A \quad$ constant in Eq. [10] \\ $B$ constant in Eq. [10] \\ $C(z)$ circular tuncion (Table I)}

$D$ chemical diffusion coefficient for cationelectron pairs in host lattice, $\mathrm{cm}^{2} \mathrm{sec}^{-1}$

$D_{+} \quad$ cation diffusion coefficient in electrolyte, $\mathrm{cm}^{2}$

F $\quad$ sec $^{-1}$

$G(\tau, Q)$ function

I total current per $\cdot \mathrm{mol} \cdot \mathrm{A} \mathrm{mole}^{-1}$

$J_{0}, J_{1} \quad$ Bessel functions

$Q \quad$ parameter, $Q=T D / r^{2}$

$S_{\mathrm{m}} \quad$ area per $\cdot \mathrm{mol} \cdot \mathrm{cm}^{2} \mathrm{~mol}^{-1}$

$T \quad$ stoichiometric discharge time, $T=n \mathbf{F} / I \mathrm{~s}$

$X$ relative cation concentration, $g=\mathrm{cV}_{\mathrm{m}} / n$

$X^{*} \quad X$ at cathode surface

$X_{d} \quad$ average $X$ before charge

$X_{D} \quad X^{*}$ at the end of peak load

$V_{m} \quad$ average molar volume of cathode compound

a constant in Eq. [6]

b constant in Eq. [6]

c concentration, mol $\mathrm{cm}^{-3}$

$c_{A}{ }^{*}, c_{C}{ }^{*}, c_{S}^{*}$ interfacial concentratons (Fig. 1), mol $\mathrm{cm}^{-3}$

$c_{+}, c_{-}$cation respectively anion concentration in electrolyte, $\mathrm{mol} \mathrm{\textrm {cm } ^ { - 3 }}$

co initial salt concentration in electrolyte, $\mathrm{mol}$

$\mathrm{cm}^{-3}$

d electrode spacing, $\mathrm{cm}$

$f$ constant in Eq. [14] and [17]

$g(\alpha) \quad$ generating function. (Table I)

$i$ current density, $\mathrm{A} \mathrm{cm}^{-2}$

$i_{C^{*}} \quad$ limiting current density at cathode, $\mathrm{A} \mathrm{cm-2}$

$j$ flux density of transported specie, $\mathrm{mol} \mathrm{\textrm {cm } ^ { - 2 }}$

$j_{+}, j_{-} \quad \begin{aligned} & \mathrm{sec}^{-1} \\ & \text { ion flux densities, } \mathrm{mol} \mathrm{cm}\end{aligned}$

$j_{0}+j_{-} \quad$ cation flux density into cathode particle, mol $\mathrm{cm}^{-2} \mathrm{sec}^{-1}$ $j_{\text {o,D }} \quad$ additional flux density due to peak load, mol $\mathrm{cm}^{-2} \mathrm{sec}^{-1}$

$m \quad$ number of particle layers

$n \quad$ limit for mole cation accepted per $\cdot$ mole host compound

$p \quad$ peak load factor Eq. [12]

$r$ particle radius or thickness $(2 r), \mathrm{cm}$

s Laplace variable

$t$ discharge time, sec

$t_{\mathrm{p}} \quad$ peak load length, sec

$x$ space coordinate, $\mathrm{cm}$

$z \quad$ dimensionless length, $z=x / r$

$z_{+}, z_{-} \quad$ numerical charge numbers

$\alpha_{\mathfrak{i}} \quad$ roots in $g(\alpha)=0$

$\eta \quad$ overvoltage

$\eta_{c} \quad$ concentration overvoltage

$\phi \quad$ electrical (galvani) potential

$\tau$ dimensionless time, $\tau=t / T$

$\tau_{\mathrm{p}} \quad t_{\mathrm{p}} / T$

$\bar{\mu} \quad$ electrochemical potential

\section{REFERENCES}

1. B. C. H. Steele, in "Fast Ion Transport in Solids," Van Gool, Editor, p. 103, North Holland, Amsterdam (1973).

2. B. C. H. Steele, in "Electrode Materials and Processes for Energy Conversion and Storage," J. D. E. McIntyre, S. Srinivasan, and F. G. Will, Editors, PV 77-6, p. 799, The Electrochemical Society Softbound Proceedings Series, Frinceton, N.J. (1977).

3a. B. S. Silbernagel and M. S. Wittingham, J. Chem. Phys., 64, 3670 (1976).

3b. B. S. Silbernagel and M. S. Wittingham, Mater. Res. Bull., 11, 29 (1976).

4. M. S. Wittingham, Prog. Solid State Chem., 12, 1 (1978).

5. J. Broadhead, in "Power Sources 4," D. H. Collins, Editor, p. 469, Oriel Press (1973).

6. M. S. Wittingham, This Journal, 123, 315 (1976).

7. J. E. Colemann, Trans. Electrochem. Soc., 90, 545 (1946).

8. A. B. Scott, This Journal, 107, 941 (1960).

9. H. Bode, A. Schmier, and D. Berndt, Z. Elektrochem., 69, 347 (1966).

10. A. Kozawa and J. F. Yeager, This Journal, 112 959 (1965).

11. J. P. Gabano, J. Segueret, and J. Laurent, This Journal, 111, 147 (1970).

12. H. Ikeda et al., "Manganese Dioxide Symposium, Vol. 1, Cleveland, 1975," A. Kozawa and R. Brodd, Editors, p. 384, I. C. Sample Office, Cleveland, Ohio (1975).

13. P. D. Lukovtsev, in "Soviet Electrochemistry," Proc. 4 Conf. in Electrochemistry, Vol. 3, p. 156, (1961).

14. D. Tuomi, This Journal, 112, 1 (1965).

15. D. M. Mac Arthur, ibid., 117, 422 (1970).

16. D. M. Mac Arthur, ibid., 117, 729 (1970).

17. F. R. van Buren, G. H. J. Broers, et al., J. Electroanal. Chem., 87, 389 (1978)

18a. B. B. Scholtens, Diss. Utrecht (1978).

18b. B. B. Scholtens and G. H. J. Broers, Submitted to $J$. Electroanal. Chem.

19. H. S. Carslaw and J. C. Jaeger, "Conduction of Heat in Solids," 2nd ed., pp. 112, 203, 242, Oxford University Press, Oxford (1976).

20. H. S. Carslaw and J. C. Jaeger, "Conduction of Heat in Solids," 2nd ed., p. 76, Oxford University Press, Oxford (1976). 
21. H. S. Carslaw and J. C. Jaeger, "Conduction of Heat in Solids," 2nd ed., p. 331, Oxford University Press, Oxford (1976).

22. D. A. Winn, J. M. Shemilt, and B. C. H. Steele, Mater. Res. Bull., 11, 559 (1976).

23. J. P. Gabano et al, in "Power Sources 2," D. H. Collins, Editor, p. 255, Pergamon Press (1966).

24. R. Jasinski, in "Advances in Electrochemistry and Electrochemical Engineering 8," P. Delahay and
C. W. Tobias, Editors, p. 291, Wiley, New York (1972).

25. B. C. H. Steele, Private communication (1978).

26. A. J. Salkind, in "Electrode Materials and Processes for Energy Conversion and Storage," J. D. E. Mcintyre, S. Srinivasan, and F. G. Will, Editors, PV 77-6, p. 711 (Table 6), The Electrochemical Society Softbound Proceedings Series, Princeton, N.J. (1977).

\title{
Heat Transfer in Lead-Acid Batteries Designed for Electric-Vehicle Propulsion Application
}

\author{
K. W. Choi ${ }^{*}$ and N. P. Yao* \\ Argonne National Laboratory, Chemical Engineering Division, Argonne, Illinois 60439
}

\begin{abstract}
Mathematical analysis has been carried out for the heat transfer in leadacid batteries designed for use in electric vehicles. This analysis has shown that the heat generated in the battery during recharge cycles may cause a noticeable rise of battery temperature in the absence of proper thermal management. The results have shown that the ratio of the temperature rise during charge is closely related to the ratio of the energy densities of the two batteries. Of the cooling methods examined, electrolyte circulation along the battery plates was found to be the most effective in removing heat and providing a uniform temperature field. Numerical solutions are provided for the engineering evaluation of heat-removal design during battery cycling processes.
\end{abstract}

In the development of advanced batteries for applications to electric-vehicle propulsion, high energy density, power density, and long cycle life are required. In a highly packed battery composed of modular cells, the amount of heat generated in the cell due to ohmic loss, polarization, and entropy production becomes noticeable during cycling processes. If the internal heat is not removed properly, this will cause a rise of cell temperature which may affect the physical and chemical properties of the electrode, electrolyte, and cell components. The cell performance and cell cycle life may also be affected by the variation of cell temperature. For example, the electrolyte (sulfuric acid) may become more corrosive at higher temperatures or the cell current may become unstable on charge due to the rise of cell temperature. Moreover, the active material $\left(\mathrm{PbO}_{2}\right)$ in the positive electrode may decompose to inactive forms depending on the temperature variation (1). These thermal effects may cause a gradual loss of cell capacity and cycle life.

In the passage of electrical current from one electrode through the electrolyte to the other electrode, heat is generated in the electrode and the electrolyte due to irreversible ohmic losses. At the electrode/ electrolyte interface, the irreversible polarization and the reversible or irreversible entropy production contribute to the heat being generated. The heat-transfer behavior across these mediums and how this heat is removed from inside the battery to the outer atmosphere will be an important consideration in cell performance and cycle life. To achieve the required cell performance and to maintain the energy density and cycle life, an understanding of temperature distribution and heat-transfer behavior within the cell may be helpful in a sophisticated thermal design for removing the internal heat in batteries.

* Electrochemical Society Active Member.

Key words: lead-acid batteries, electric-vehicle propulsion, heat transfer, electrolyte circulation.
Baker, Gidaspow, and Wason (2) have examined general thermal behavior in fuel cells and batteries and the associated mathematical techniques for obtaining analytical solutions for fuel cells and batteries. The analytical method is, however, limited by the characteristics of the mathematical functions and the boundary conditions. In the present analyses, mathematical models were developed for the studies of battery thermal behavior and heat-release processes; numerical solutions were obtained by use of the finite difference method. Numerical solutions are provided and these are discussed in terms of engineering applications.

\section{Thermal Phenomena in a Composite Lead-Acid Battery during Recharge Processes}

During electrode cycling processes, the electrical current passes through the electrode to the electrolyte, and the electrochemical reaction takes place on the electrode surface. Heat is generated at the electrode/ electrolyte interface owing to the surface polarization and entropy contributions and is also generated in the electrolyte and the solid electrode phases due to the ohmic losses. Previous study (3) has shown that the maximum temperature difference across the solid electrode and the electrolyte during charging in a porous $\mathrm{PbO}_{2}$ electrode (the apparent current density is $\sim 20 \mathrm{~mA} / \mathrm{cm}^{2}$ ) is less than $10^{-4}{ }^{\circ} \mathrm{C}$ and approaches a steady value within a few seconds. Thus, at any location within the porous $\mathrm{PbO}_{2}$ electrode, the temperatures of the electrode and electrolyte may be regarded as the same. Also, for a composite lead-acid battery, the cell may be treated as a homogeneous medium with the averaged physical parameters (density, specific heat, thermal conductivity, and electrical conductivity), and the heat generated may be averaged over the battery. This approximation is used in the following treatment for a composite lead-acid battery. 